\title{
Does Centella Asiatica Have Antiaging Activity in Skincare Products?
}

\author{
Gabriella Chandrakirana Krisnamurti ${ }^{1}$ Dewi Ratih Tirto Sari ${ }^{2,3 *}$
}

\author{
${ }^{1}$ Biotechnology Program, School of Bioresources and Technology, King Mongkut's University of Technology \\ Thonburi, 10150 Bang Khun Thian, Bangkok, Thailand \\ ${ }^{2}$ Department of Biology, Faculty of Mathematics and Natural science, Brawijaya University Jl. Veteran Malang, \\ Ketawanggede, Malang, Jawa Timur. Indonesia. 65145 \\ ${ }^{3}$ Research Center of Smart Molecule of Natural Genetics Resources, Brawijaya University, Jl. Veteran Malang, \\ Ketawanggede, Malang, Jawa Timur. Indonesia. 65145
}

*Corresponding author. Email: dratih303@gmail.com

\begin{abstract}
This study provided the mechanism of two main compounds of $C$. asiatica to prevent aging processes by computational analysis. Castilliferol and castillicetin were retrieved from PubChem database, matrix metalloproteinase or MMP involved MMP3, MMP9, and MMP12 also taken out from protein data bank (PDB). Two compounds and MMPs were docked using HEX 8.0 version and analyzed using Discovery Studio 4.1. Castilliferol and castillicetin bound to MMPs (MMP3, MMP9, and MMP12) in several amino acid residues, which were identified as active sites and catalytic sites of MMP3 and MMP9. In contrast, castilliferol and castillicetin inhibited MMP12 allosterically and might change the MMP conformation and reduce the MMP's activities. The binding free energy among Castilliferol and castillicetin with MMPs performed varied values binding free energy with hydrogen bond, hydrophobic interaction, and electrostatic. Castillicetin demonstrated lower binding free energy in MMP3 and MMP12, while castilliferol showed lower binding free energy in MMP9. Low binding free energy predicted that the compounds have tight ligand - protein interaction. This study suggested that C.asiatica compounds performed antiaging and further in vitro or in vivo analysis are required.
\end{abstract}

Keywords: Aging, Castilliferol, Castillicetin, Centella asiatica, matrix metalloproteinase.

\section{INTRODUCTION}

Aging is a natural phenomenon that caused by extrinsic and intrinsic factors. Extrinsic factors including light exposure, pollution, free radicals, chemichal, toxins and others accumulated overtime and leads to skin structural and physiological alterations [1-4]. This phenomenon mainly caused by reactive oxygen species (ROS). It is responsible for oxidative stress and dermal/epidermal layer inflammation. It could effect on an activation of collagenase and elastase enzyme, causing protein damage. Free radicals of ROS also can cause degradation of hyaluronic acid which is important for skin hydration and its firmness. Besides that, free radicals and UV light exposure change the skin appearance including skin pigmentation, wrinkles and gradually loss of skin elasticity. Ultra violet exposure induced ROS production and inactivated receptor protein tyrosyne phosphatase lead to MAPK pathway resulted repression of collagen production by expressing MMPs genes [5].
MMPs gene encoded the dermal enzyme, matrix metalloproteinase (MMP) that promotes skin aging. It works by degrading extracellular matrix (ECM) protein. High level of MMP due to high ROS level, causing collagen degradation, collagen fragmentation, and elastic fibre degradation. Several treatments are developed to prevent aging, such as daily skin care, sun protection, antioxidant, cell regulators, chemichal peeling, injectable biostimulation, preventing of dynamic wrinkles, and others [1-3].

In the last decade, antioxidant was developed to prevent the aging process, resulting in reduce any systemic diseases [6,7]. Antioxidant from nutrition of dietary food might have more effective and low risk for skin treatment [4,5]. Recently, bioactive compounds from traditional herbs has been identified for its potency as antioxidant. It could be useful for cosmetic ingredients. The traditional herb Centella asiatica or named 'pegagan' in Indonesia is one of the medicinal 
herb belong to the family Apiaceae. 'Pegagan' is famous for the treatment of skin diseases, but it also has other potency such as for wound healing, dysentery, bronchitis, urethritis, anti-allergic and anti-cancer [8-10]. It has been reported that $C$. asiatica extract has ability in inhibiting hyaluronidase, elastase, and MMP-1 enzyme [11]. Recently, two new flavonoids were found in $C$. asiatica named castilliferol and castillicetin. Based on previous study, castilliferol and castillicetin shows promising antioxidant activity indicated by high $\mathrm{IC}_{50}$ value [8]. Nowadays, $C$. asiatica extract was used for skin care treatments because of its ability to induce woud healing with no irritation effect [7]. However, the molecular mechanism of $C$. asiatica extract are not explored yet. The recent study of collagenase and $C$. asiatica leads to assumption of the potency as collagenase inhibitor and elastase inhibitor [11]. The new flavonoids of $C$. asiatica also interesting to be identified for its potency. In addition, the study about new flavonoids in inhibiting collagenase and elastase is not established yet. Therefore, this study identified the potency of two new flavonoids namedcastilliferol and castillicetin as antiaging agent by inhibiting MMPs (MMP-3, MMP-9, and MMP-12).

\section{MATERIALS AND METHODS}

The analysis was done by in-silico $[12,13]$. The 3D proteins structure of MMP-3 (2D10), MMP-9 (1L6J), and MMP-12 (1JIZ) were retrieved from PDB database. The proteins were prepared by removing water molecules and ligands using Discovery Studio 4.1. Two new flavonoids of Centella asiatica named castillicetin (CID102394640) and castilliferol (CID10526707) were retrieved from PubChem database in SDF format. The ligands were prepared to be PDB format with PyRx 0.8 [14]. Each flavonoids were docked with each MMP protein using HEX 8.0. The docking results were visualized using Discovery Studio 4.1 in 2D and 3D format.

\section{RESULTS}

The two new flavonoids from $C$. asiatica, castilliferol and castillicetin, were assumed to have potency in preventing aging. Here, we docked the flavonoids with MMP-3, MMP-9, and MMP-12, known as aging protein. The docking result showed the ability of castilliferol and castillicetin to bind with MMP-3, MMP-9, and MMP-12 protein (Table 1). As shown in the table, the castilliferol and castillicetin could inhibit the MMP by binding on the protein's active sites or catalytic sites. The low energy indicated strong binding and proved the ability of those flavonoids in preventing aging.

The castilliferol binding to MMP-3 (-340.2 kJ/mol) was as strong as castillicetin - MMP-3 complex (347.9 $\mathrm{kJ} / \mathrm{mol}$ ) in binding with MMP-3. Both flavonoids also interacted with the catalytic domain of MMP-3. The presence of the van der Waals bond in both interactions increased the stability of its interaction (Figure 1a, 1b). The flavonoids were also bound to a similar amino acid residue, such as Leu164 with a hydrophobic bond.

As shown in the result, the castilliferol - MMP-9 ($313.9 \mathrm{~kJ} / \mathrm{mol}$ ) showed ability to interact with the active site of the protein through Arg98 amino acid with a hydrophobic bond (Figure 1c). The binding energy is relatively higher than castillicetin - MMP-9 (-309.6 $\mathrm{kJ} / \mathrm{mol}$ ). In contrast, castillicetin could interact with five amino acid residues in active sites of MMP-9. The lower binding energy score was possibly caused by the presence of the unfavorable bond (Figure 1d).

Table 1. The interaction among castilliferol and castillicetin with MMP-3, MMP-9, and MMP-12

\begin{tabular}{|c|c|c|c|c|}
\hline Protein & Ligand & Name & Category & $\begin{array}{l}\text { Binding Free } \\
\text { Energy }(\mathrm{KJ} / \mathrm{mol})\end{array}$ \\
\hline \multirow{4}{*}{ MMP-3 } & \multirow[b]{2}{*}{ Castilliferol } & GLU202, TYR223 & Hydrogen Bond & \multirow[b]{2}{*}{-340.2} \\
\hline & & $\begin{array}{l}\text { TYR223, VAL163, LEU164, LEU222, } \\
\text { LEU197 }\end{array}$ & Hydrophobic & \\
\hline & \multirow[t]{2}{*}{ Castillicetin } & $\begin{array}{l}\text { THR193, THR215, GLU202, ASN162, } \\
\text { THR215 }\end{array}$ & Hydrogen Bond & \multirow[t]{2}{*}{-347.9} \\
\hline & & LEU164, THR215, HIS201, VAL198 & Hydrophobic & \\
\hline \multirow{4}{*}{ MMP-9 } & \multirow{2}{*}{ Castilliferol } & ARG51, ARG95, GLU47 & Electostastic & \multirow{2}{*}{-313.9} \\
\hline & & LEU44, ARG95, ARG98, ARG51 & Hydrophobic & \\
\hline & \multirow[b]{2}{*}{ Castillicetin } & TYR128, TYR134, ASP131, PRO133 & Hydrogen Bond & \multirow[b]{2}{*}{-309.6} \\
\hline & & $\begin{array}{l}\text { LEU132;PRO133, PRO133, VAL218, } \\
\text { PRO219, PRO272, ARG279 }\end{array}$ & Hydrophobic & \\
\hline \multirow{5}{*}{ MMP-12 } & \multirow{3}{*}{ Castilliferol } & ZN257 & Other & \multirow{3}{*}{-324.2} \\
\hline & & TYR141 & Hydrogen Bond & \\
\hline & & HIS119, TYR141, ILE81, LEU115 & Hydrophobic & \\
\hline & \multirow{2}{*}{ Castillicetin } & ALA83, ALA135, VAL136, LYS142 & Hydrogen Bond & \multirow{2}{*}{-332.1} \\
\hline & & ILE81, TYR141, HIS119, LEU115 & Hydrophobic & \\
\hline
\end{tabular}



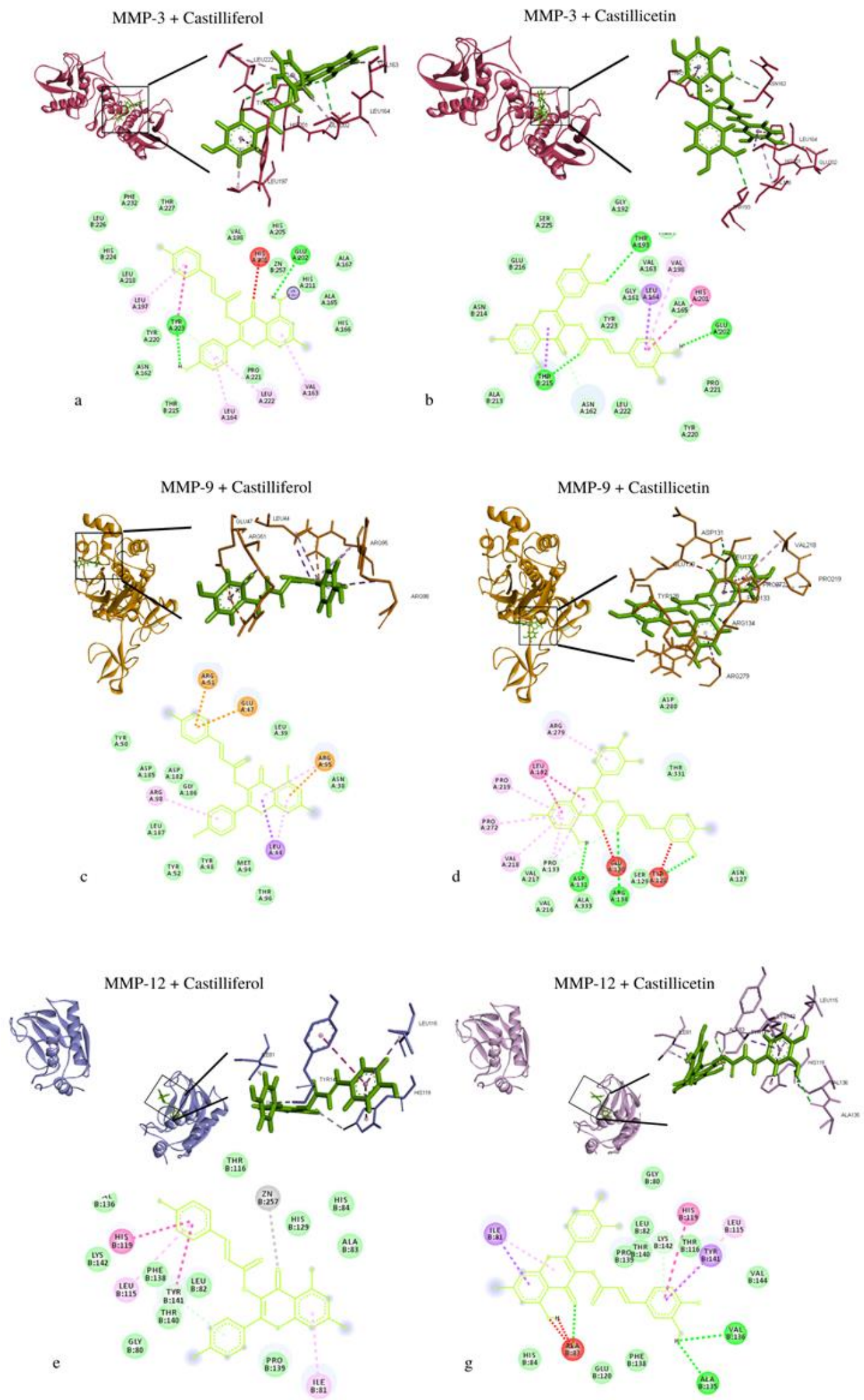

Figure 1. The binding poses of castilliferol and castillicetin to MMP3, MMP9, and MMP12 proteins. 
Compared to MMP3 and MMP9, the flavonoids did not interact with amino acid residues in the active site and catalytic site of the MMP-12 (Figure 1e, 1f). The interaction of castilliferol with MMP-12 $(-324.2 \mathrm{~kJ} / \mathrm{mol})$ on the two amino acid named Zn257 and Tyr141. The castillicetin - MMP-12 $(-332.1 \mathrm{~kJ} / \mathrm{mol})$ showed stronger binding than castilliferol. Despite the presence of the unfavorable bond, the castillicetin binding with MMP-12 still show stronger binding than castilliferol.

\section{DISCUSSION}

Matrix metalloproteinases (MMPs) is an enzyme responsible for collagen degradation in extracellular matrix. MMPs consisted of some distinct domains that performed several physiological process including collagenase, angiogenesis, wound healing and others [24,15-17]. The inhibition of MMPs here could be one of the mechanism to prevent aging. MMPs could be activated by high ROS level [18]. ROS activate the mitogen-activated protein kinase (MAPK) family, inducing transcription factor, activator protein-1 (AP-1). Activation of AP-1 plays major role in regulating MMP1, MMP-3, MMP-9, MMP-12. The inhibition of MMP-3, MMP-9, and MMP-12 assumed could reduce collagen degradation and fragmentation, also increase the functional elastic fiber [18]. According to the result, it could be assumed that two flavonoids from $C$. asiatica has inhibitory activity against collagenase and elastase through MMP-3, MMP-9, and MMP-12. It indicates the potency of C.asiatica for cosmetic. Previous study reported that the crude extract of $C$. asiatica is effective for wound healing by promoting proliferation of fibroblast and collagen [7,19]. The binding of castilliferol and castillicetin to MMP-3 and MMP-9 occurred in the active sites and catalytic sites [20,21]. The inhibition in the active site or catalytic site with strong binding indicating the ability of a compound to interfere an enzymatic process [22]. The inhibition in catalytic or active site could directly inhibit the activity of a protein (23). Both flavonoids showed high potency as MMPs inhibitor. Especially to the MMP-3 and MMP-9, indicating high potency of castilliferol and castillicetin as collagenase inhibitor. Degradation of collagen by MMP9 shows up to be the main factor of aging in skin tissue [24]. However, the elastase inhibitor of castilliferol and castillicetin more likely low due to the absent of amino acid binding to catalytic or active sites of MMP-12 [25]. Previous study performed that there were synthetic and natural MMP inhibitors, synthetic inhibitor including tetracycline and biphosponate, while natural inhibitor such as flavonoids, isoflavones, and shark cartilages [1517]. Caffeines based cosmetics also reported turned down skin photoaging processe through inhibiting collagenase, elastase, and tyrosinase both in vitro and in silico assays [16]. Exopolysaccharides of Lactobacilli also down- regulated MMP2, 3, 9, and MMP10 and showed high anti-collagenase and antielastase [15]. Phyllanthus emblica L. (Euphorbiaceae) (amla) and Manilkara zapota L.P. Royen extract reportes have potential activities as anti-collagenase and anti-elastase [26].

The in silico study also supported by previous in vitro study. According to the in vitro study, C. asiatica showed potential ability in increasing collagen 1 type expression, leading to wound healing. C. asiatica extract also showed high inhibition activity against elastase and collagenase [11]. This study suggested that two new flavonoids, castilliferol and castillicetin performed inhibition to MMP3, MMP9 and MMP12 and revealed antiaging activity.

\section{AUTHORS' CONTRIBUTIONS}

GCK and DRTS contributed for research designing, analysis and drafting the manuscript.

\section{ACKNOWLEDGMENTS}

This research supported by inijurnal.co research community funding. Authors thank to inijurnal.co team for research discussion.

\section{REFERENCES}

[1] Tejaswini R. Treatment Strategies in the Management of Proactive Skin Health and Antiaging Improvement- A Review. Clinical Dermatology Open Access Journal. 2020;5(3). DOI: $10.23880 / C D O A J-16000215$.

[2] Jadoon S, Karim S, Asad MHH Bin, Akram MR, Kalsoom Khan A, Malik A, et al. Anti-aging potential of phytoextract loaded-pharmaceutical creams for human skin cell longetivity. Oxidative Medicine and Cellular Longevity. 2015;2015. doi: 10.1155/2015/709628.

[3] Ganceviciene R, Liakou AI, Theodoridis A, Makrantonaki E, Zouboulis CC. Skin anti-aging strategies. 2012;4(3):308-19. https://www.ncbi.nlm.nih.gov/pmc/articles/PMC 3583892/.

[4] Berger MM. Can oxidative damage be treated nutritionally? Clinical Nutrition. 2005;24(2):17283. doi: 10.1016/j.clnu.2004.10.003.

[5] Zhang S, Duan E. Fighting against Skin Aging: The Way from Bench to Bedside. Cell Transplantation. 2018;27(5):729-38. doi: $10.1177 / 0963689717725755$.

[6] Cui X, Lin Q, Liang Y. Plant-Derived Antioxidants Protect the Nervous System From Aging by Inhibiting Oxidative Stress. Frontiers in 
Aging Neuroscience. 2020;12:209. doi: 10.3389/fnagi.2020.00209.

[7] Sun B, Wu L, Wu Y, Zhang C, Qin L, Hayashi M, et al. Therapeutic Potential of Centella asiatica and Its Triterpenes: A Review. Frontiers in Pharmacology. 2020;11. https://www.ncbi.nlm.nih.gov/pmc/articles/PMC $7498642 /$

[8] Subban R, Veerakumar A, Manimaran R, Hashim $\mathrm{KM}$, Balachandran I. Two new flavonoids from Centella asiatica (Linn.). Journal of Natural Medicines. 2008;62(3):369-73. DOI: $10.1007 / \mathrm{s} 11418-008-0229-0$.

[9] Zainol MK, Abd-Hamid A, Yusof S, Muse R. Antioxidative activity and total phenolic compounds of leaf, root and petiole of four accessions of Centella asiatica (L.) Urban. Food Chemistry. 2003;81(4):575-81. https://doi.org/10.1016/S0308-8146(02)00498-3.

[10] Zofia NŁ, Martyna ZD, Aleksandra Z, Tomasz B. Comparison of the Antiaging and Protective Properties of Plants from the Apiaceae Family. Oxidative Medicine and Cellular Longevity. 2020;2020.

https://doi.org/10.1155/2020/5307614.

[11] Nema NK, Maity N, Sarkar BK, Mukherjee PK. Matrix metalloproteinase, hyaluronidase and elastase inhibitory potential of standardized extract of Centella asiatica. Pharmaceutical Biology. 2013;51(9):1182-7. doi: 10.3109/13880209.2013.782505.

[12] Bare Y, Indahsari LIN, Sari DRT, Watuguly T. In Silico Study: Potential Prediction of Curcuma longa And Cymbopogon citratus Essential Oil As Lipoxygenase Inhibitor. JSMARTech. 2021;02(02):76-80.

https://doi.org/10.21776/ub.jsmartech.2021.002.0 2.75 .

[13] Chandrakirana Krisnamurti G, Fatchiyah F. The Biological Function Prediction of The 10-gingerol Compound of Ginger in Inhibiting Cyclooxygenase-2 Activity. The Journal of Pure and Applied Chemistry Research. 2020;9(3):22232.

http://dx.doi.org/10.21776/ub.jpacr.2020.009.03. 547.

[14] Dallakyan S, Olson AJ. Small molecule library screening by docking with PyRx. Methods Mol Biol. 2015;1263:243-50. doi: 10.1007/978-14939-2269-7_19.
[15] Shirzad M, Hamedi J, Motevaseli E, Modarressi MH. Anti-elastase and anti-collagenase potential of Lactobacilli exopolysaccharides on human fibroblast. Artificial Cells, Nanomedicine and Biotechnology 2018;46(sup1):1051-61. Available from: https://doi.org/10.1080/21691401.2018.1443274

[16] Eun Lee K, Bharadwaj S, Yadava U, Gu Kang S. Evaluation of caffeine as inhibitor against collagenase, elastase and tyrosinase using in silico and in vitro approach. Journal of Enzyme Inhibition and Medicinal Chemistry [Internet]. 2019;34(1):927-36. Available from: https://doi.org/10.1080/14756366.2019.1596904

[17] Jabłońska-Trypuć A, Matejczyk M, Rosochacki S. Matrix metalloproteinases (MMPs), the main extracellular matrix (ECM) enzymes in collagen degradation, as a target for anticancer drugs. Journal of Enzyme Inhibition and Medicinal Chemistry. 2016;31:177-83. doi: 10.3109/14756366.2016.1161620.

[18] Shin JW, Kwon SH, Choi JY, Na JI, Huh CH, Choi HR, et al. Molecular mechanisms of dermal aging and antiaging approaches. International Journal of Molecular Sciences. 2019;20(9). doi: 10.3390/ijms20092126.

[19] Sawatdee S, Choonchuay K, Chanthorn W, Srichana T. Evaluation of the topical spray containing Centella asiatica extract and its efficacy on excision wounds in rats. Acta Pharmaceutica. 2016;66:233-44. doi 10.1515/acph-2016-0018.

[20] Elkins PA, Yen SH, Smith WW, Janson CA, D'Alessio KJ, McQueney MS, et al. Structure of the C-terminally truncated human ProMMP9, a gelatin-binding matrix metalloproteinase. Acta Crystallographica Section D: Biological Crystallography. 2002;58(7):1182-92. doi $10.1107 /$ s0907444902007849.

[21] Kohno T, Hochigai H, Yamashita E, Tsukihara T, Kanaoka M. Crystal structures of the catalytic domain of human stromelysin-1 (MMP-3) and collagenase-3 (MMP-13) with a hydroxamic acid inhibitor SM-25453. Biochemical and Biophysical Research Communications. 2006;344(1):315-22. doi 10.1016/j.bbrc.2006.03.098.

[22] Krisnamurti GC, Fatchiyah F. Interaction of acetaminophen and caffeine towards cyclooxygenase-2 (COX-2) in inhibition of prostaglandin (PGH 2 ) synthesis. In: Journal of Physics: Conference Series. 2019. p. 012004. 
https://iopscience.iop.org/article/10.1088/17426596/1146/1/012004.

[23] Carli M, Sormani G, Rodriguez A, Laio A. Candidate Binding Sites for Allosteric Inhibition of the SARS-CoV-2 Main Protease from the Analysis of Large-Scale Molecular Dynamics Simulations. Journal of Physical Chemistry Letters. 2021;12(1):65-72. https://doi.org/10.1021/acs.jpclett.0c03182.

[24] Buranasudja V, Rani D, Malla A, Kobtrakul K, Vimolmangkang $\mathrm{S}$. Insights into antioxidant activities and anti-skin-aging potential of callus extract from Centella asiatica (L.). Scientific Reports. $2021 ; 11$. https://doi.org/10.1038/s41598-021-92958-7.
[25] Nar H, Werle K, Bauer MMT, Dollinger H, Jung B. Crystal structure of human macrophage elastase (MMP-12) in complex with a hydroxamic acid inhibitor. Journal of Molecular Biology. 2001;312(4):743-51.

doi: 10.1006/jmbi.2001.4953.

[26] Pientaweeratch S, Panapisal V, Tansirikongkol A. Antioxidant, anti-collagenase and anti-elastase activities of Phyllanthus emblica, Manilkara zapota and silymarin: an in vitro comparative study for anti-aging applications. Pharmaceutical Biology. 2016;54(9):1865-72. doi: 10.3109/13880209.2015.1133658. 